\title{
The Application of Ultraviolet Spectrophotometry (UV) on Some Water Mite Species (Acari, Hydrachnidia)
}

\author{
Ferruh Așçı ${ }^{*}$, Gülderen Uysal Akkuş² \\ ${ }^{1}$ Molecular Biology and Genetics Department, Afyonkarahisar, Turkey \\ ${ }^{2}$ Chemistry Department, Afyon Kocatepe University, Afyonkarahisar, Turkey \\ Email: ^f_asci@aku.edu.tr
}

How to cite this paper: Aşçı, F. and Akkuş, G.U. (2017) The Application of Ultraviolet Spectrophotometry (UV) on Some Water Mite Species (Acari, Hydrachnidia). Advances in Bioscience and Biotechnology, 8, 142-148.

https://doi.org/10.4236/abb.2017.84011

Received: March 3, 2017

Accepted: April 27, 2017

Published: April 30, 2017

Copyright (c) 2017 by authors and Scientific Research Publishing Inc. This work is licensed under the Creative Commons Attribution International License (CC BY 4.0).

http://creativecommons.org/licenses/by/4.0/

\begin{abstract}
In this study an ultra violet analysis, which is a spectrophotometric method, was applied for the first time as a structural analysis of the group. The following species were collected from Karamik Lake in Afyon Province, Turkey between April and August, 2015, Hydryphantes flexiosus, Hydrodroma despiciens, Georgella helvatica, Eylais infundibulifera, Hygrobates nigromacutlatus and Torrenticola brevirostris. These species were separately analyzed by Ultraviolet Spectrophotometer (US) and the results assessed using graphical readings. The affiliations between the species were read from the graphical curves of each species and then compared in terms of the curves.
\end{abstract}

\section{Keywords}

Water Mites, Acari, Hydrachnidia, UV, Analysis

\section{Introduction}

Water mites occupy a significant position in the food chain and are also known as bioindicators of clean water sources. They belong to a branch of arthropoda commonly found in inland waters with more than 6000 species currently recognized [1]. Genetic, chemical and ecological studies have been carried out on this group in recent years in addition to classical-systematic studies [2]-[7]. The main reason for selecting water mites for this study is that these species represent the most fundamental level of life in lakes and flowing water systems [3].

As a result, they are a significant factor in many ecological studies. Other reasons are their role as biological indicator organisms of clean water ecosystems and the classical systematical problems encountered in the group. Morphologi- 
cally, water mites have elliptical or egg shaped bodies with a flattened dorsum and abdomen. Larvae have three pairs of legs while nymphs and adults have four. Water mites have a complex life cycle and their eggs are found on many aquatic plants. During their larval phase they co-exist with different animal some of these species as ectoparasites. There is a particular importance in determining their habitats and communities in lakes and stagnant waters such as ponds as well as flowing waters [8].

The samples used in this study were collected from Karamık Lake in Afyon Province, Turkey between April and August, 2015 [9]. The collected species were analyzed using the UV (Ultraviolet Spectrophotometer) technique based on the absorption of UV rays by materials.

The basic logic of UV consists of transmitting light through a prepared dilution and determining the amount of light absorbed by that dilution. The higher the amount of agent contained in the dilution, the more light is absorbed by the dilution. The spectrophotometer is able to acquire quantitative information regarding the amount of the relevant ingredient in the dilution by determining the intensity of the light that passes through the dilution but is not absorbed. UV and spectrophotometric measurements in the visible area are the most widely used methods in qualitative and quantitative analyses. They are used to study whether functional groups are available for the determination of the structures of pure substances $(\mathrm{C}=\mathrm{O}, \mathrm{C}=\mathrm{C}$, conjugation, etc.) as well as determining the position of a functional group within a compound. They are also used to measure the quantitative concentration of a pure substance or the concentration of compounds in a mixture [10].

\section{Materials and Methods}

The water mites used in the study were collected from Karamik Lake in Afyon Province between May and August, 2015 using special gauze butterfly nets, Pasteur pipettes, steel sieves and other equipment. The samples were separated in the laboratory according to species with the help of a microscope. The species were washed with distilled water and dried in sterile dishes. Precision scales were used to weigh the dried remains and a few drops of $(0.5 \mathrm{~mL})$ concentrated $\mathrm{HNO}_{3}$ (nitric acid) were added onto approximately $10 \mathrm{mg}$ of water mite sample. Subsequently this was diluted with distilled water. The diluted solution was placed in micro tubs and weighed against diluted nitric acid with UV (Shimadzu UV-1700 pharma). The analysis results were assessed graphically at $200-400$ $\mathrm{nm}$.

\section{Results and Discussion}

UV (Ultraviolet spectrophotometer) is another of the spectrophotometric methods that is used primarily for the analysis of chemical substances [11] [12] [13] [14]. The essence of the method is diluting solid and liquid substances with appropriate solvents (water, alcohol, chloroform, etc.) and reading the wave lengths with a spectrophotometric device. The use of this method particularly on 
invertebrates is quite recent and thus this study is pioneering in terms of the acaroid group. In some UV studies researchers used different doses of UV rays on different levels of invertebrates (especially small ones) in natural and laboratory environments and assessed the results [15] [16] [17] [18].

One of the main reasons for selecting water mites species in this study is to contribute to the solution of many systemic problems encountered in this group. Because most classical taxonomic methods are inadequate for detection and diagnosis in this group. Therefore, this method may be useful in solving these problems. Six different water mite species (Acari, Hydrachnidia) were used in the study. These species are Hydryphantes flexiosus (1), Hydrodroma despiciens (2), Georgella helvatica (3), Eylais infundibulifera (4), Hygrobates nigromacutlatus (5) and Torrenticola brevirostris (6). The UV (ultraviolet spectrophotometer) method used in the study was applied separately to each of the species. The spectroscopic results were read as a wave length graphic versus absorbance. While the vertical axis in the graphics displayed absorbance percentage the horizontal axis displayed the wave length of the substance in nm. As a result of an examination of the wave length graphic versus absorbance of water mite species it is evident that the vertical axis or absorbance values of the first species, $\mathrm{Hy}_{\text {- }}$ dryphantes flexiosus, varied between -0.920 and 2.00 while the horizontal axis wave length varied between 220 and $330 \mathrm{~nm}$ (Figure 1). The equivalent parameters for Hydrodroma despiciens varied between -0.97 and 1.70 on the vertical axis and between 215 and $340 \mathrm{~nm}$ on the horizontal axis (Figure 2). The values for Georgella helvatica varied between -0.800 and 4.00 on the vertical axis and between 210 and 320 on the horizontal axis (Figure 3). The values of the Eylais infundibulifera species varied between -0.840 and 4.00 on the vertical axis and

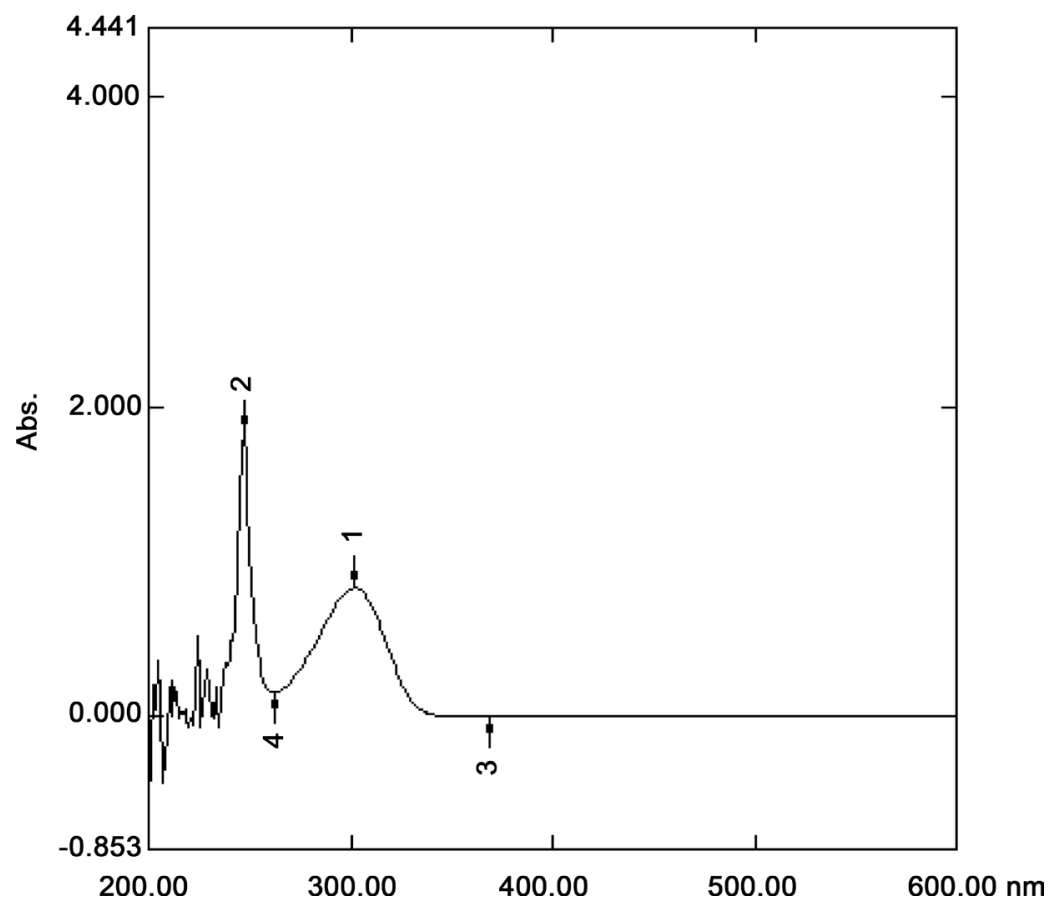

Figure 1. Hydryphantes flexuosus. 


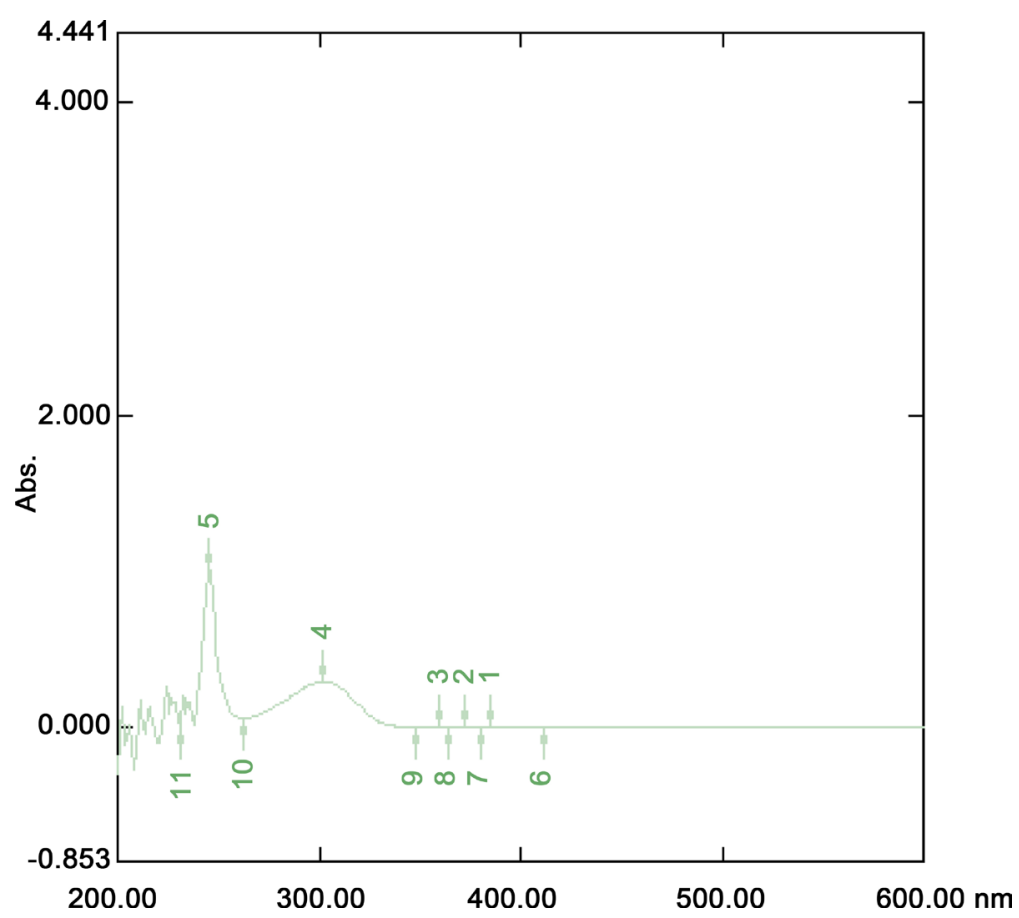

Figure 2. Hydrodroma despiciens.

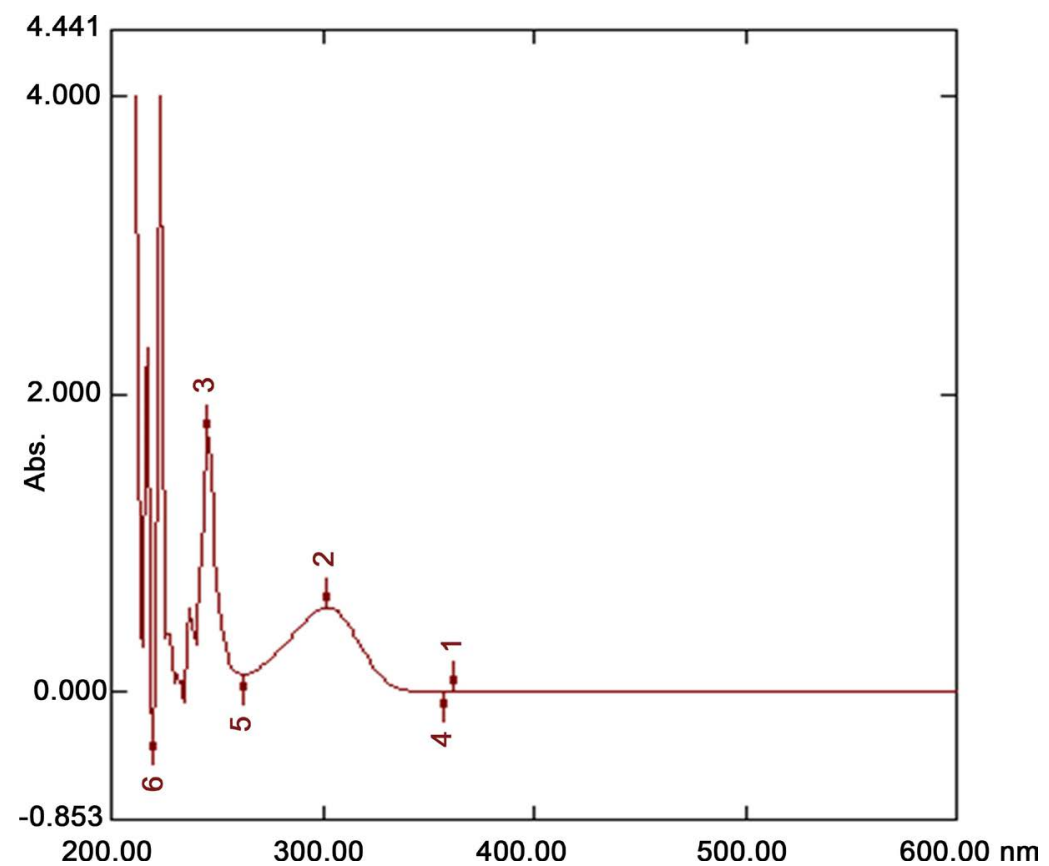

Figure 3. Georgella Helvetica.

between 205 and $330 \mathrm{~nm}$ on the horizontal axis (Figure 4). The figures for $\mathrm{Hy}^{-}$ grobates nigromacutlatus varied between 0.30 and 1.95 on the vertical axis and between 210 and 350 on the horizontal axis (Figure 5).

The last species of the study was Torrenticola brevirostris and the figures for the vertical axis were $0.20-2.20$ and between 230 and 320 for the horizontal axis (Figure 6). The wave lengths of the horizontal axis specify the electronic transmission level in the molecules of the creature's structure. This in turn provides 
information about the existence of the functional groups $\mathrm{C}=\mathrm{O}, \mathrm{C}=\mathrm{N}$ etc. in the structure of the creature. The maximum wave length electronic transmissions observed in these groups are $n-\pi^{*}, \pi-\pi^{\star}$ transmissions. These structures are usually observed in amino acids that are the keystones of proteins and particularly in chitin structures. A study of the graphics of all these species shows that the numerical data are similar to one another. The reason for this is that these species are all systematically closely related groups. Therefore the acquired graphical values share a close similarity. However, a careful study of the values of

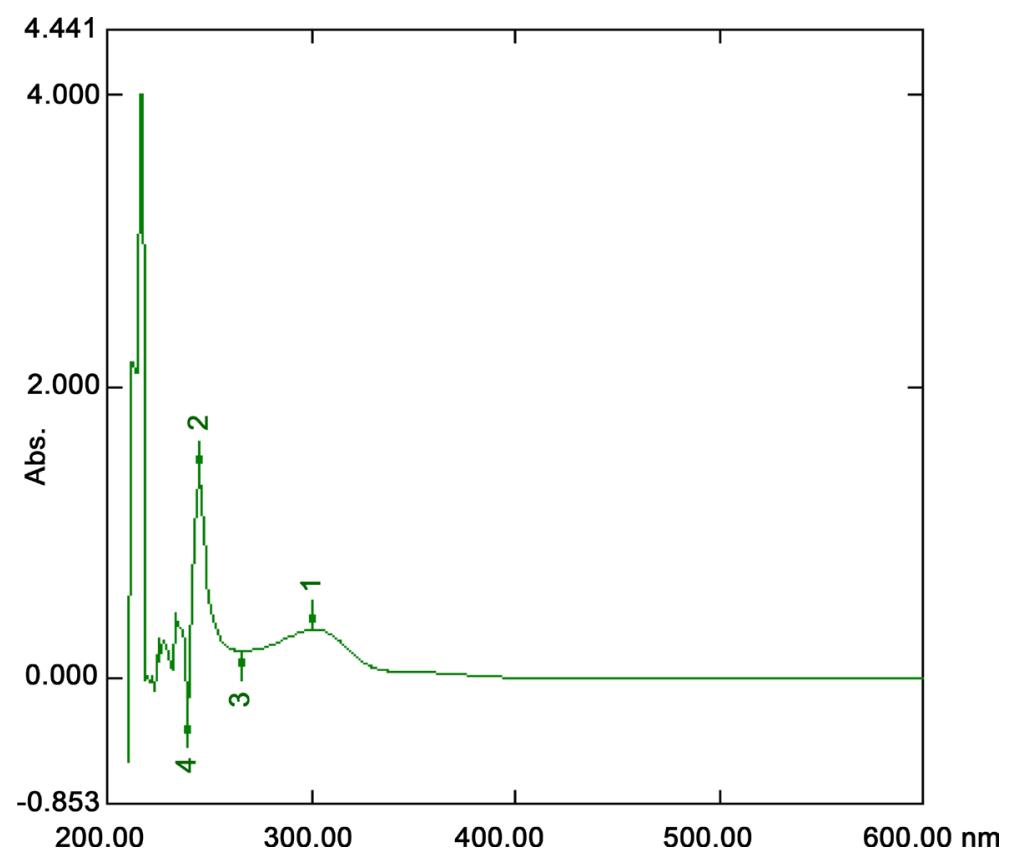

Figure 4. Eylais infundibulifera.

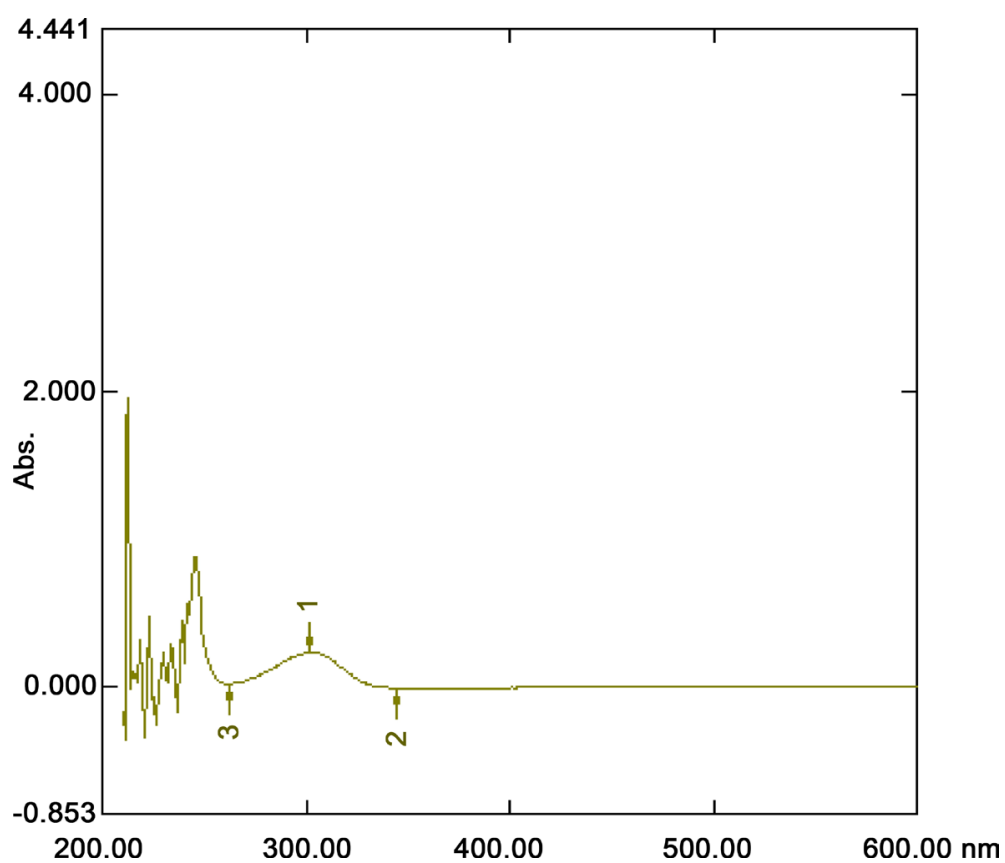

Figure 5. Hygrobates nigromaculatus. 


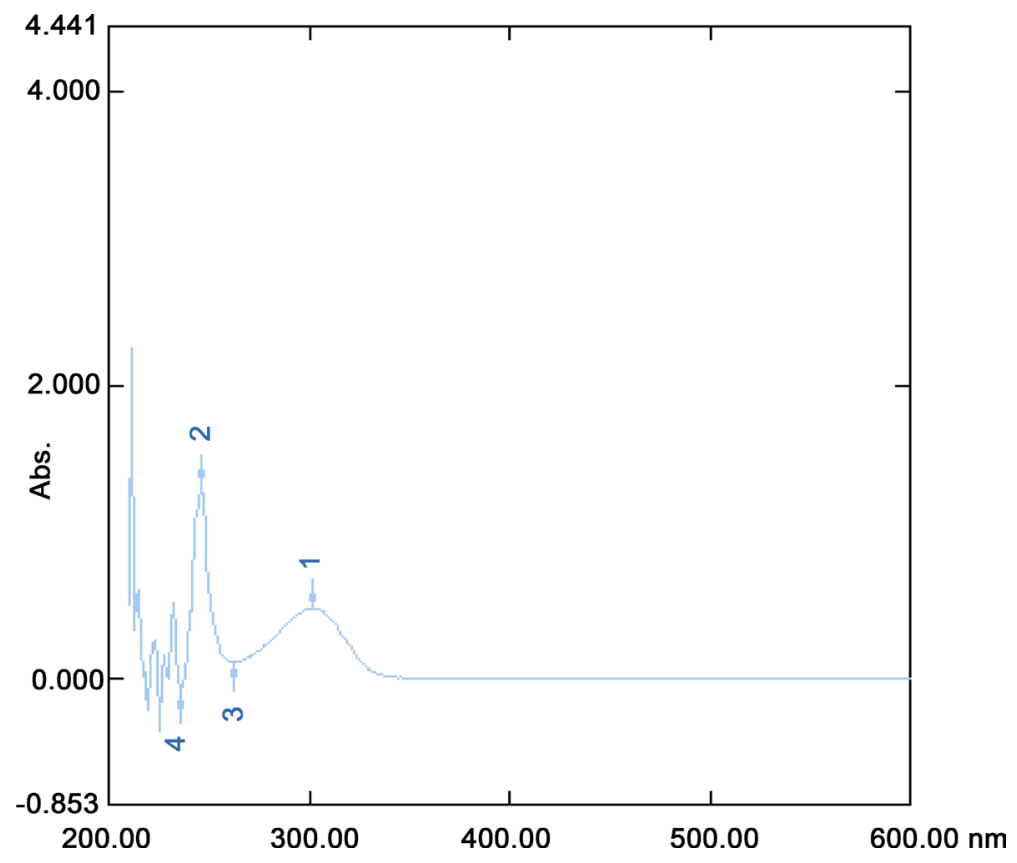

Figure 6. Torrenticola brevirostris.

absorbance and wave length graphics points to a systematic separation generated by the small amount of differences among the species. The expectation here is that the similarity is high while the differences are minor. This expectation coincides with the numerical values. The reason for this is that the similarity of data for groups that are systematically close to one another increases while the level of difference diminishes. The graphical values generated for each of the seven species used in this study indicate that those values are particular to the relevant species. Under the circumstances, using this method for the resolution of the controversial systematic problems surrounding this group as well as for studies regarding the phylogenetic affiliations between the species is worthy of consideration.

Figures 1-6, The UV spectrum of species at $200-400 \mathrm{~nm}$.

\section{References}

[1] Smith, I.M. and Cook, D.R. (1991) Water Mites. In: Thorp, J.H. and Covich, A.P., Eds., Ecology and Classification of North American Freshwater Invertebrates, Academic Press, San Diego, 523-592.

[2] Onrat, S.T., Asçi, F. and Ozkan, M. (2006) A Cytogenetics Study of Hydrodroma Despiciens Müller, 1776 Acari, Hydrachnellae, Hydrodromidae. Genetics and Molecular Research, 30, 342-349.

[3] Aşçi, F., Akkuş, G.U. and Yaman, İ. (2016) Accumulation of Heavy Metals by a Common Water Mite Hydrodroma Despiciens (OF Müller, 1776) in Laboratory Condition. Pakistan Journal of Zoology, 48, 345-348.

[4] Bohonak, A.J., Smith, B.P. and Thornton, M. (2004) Distributional, Morphological and Genetic Consequences of Dispersal for Temporary Pond Water Mites. Freshwater Biology, 492, 170-180. https://doi.org/10.1111/j.1365-2426.2003.01177.x

[5] Martin, P., Dabert, M. and Dabert, J. (2010) Molecular Evidence for Species Separation in the Water Mite Hygrobates Nigromaculatus Lebert, 1879 Acari, 
Hydrachnidia, Evolutionary Consequences of the Loss of Larval Parasitism. Aquatic Sciences, 723, 347-360. https://doi.org/10.1007/s00027-010-0135-x

[6] Di Sabatino, A., Gerecke, R. and Martin, P. (2000) The Biology and Ecology of Lotic Water Mites Hydrachnidia. Freshwater Biology, 441, 47-62. https://doi.org/10.1046/j.1365-2427.2000.00591.x

[7] Asçi, F., Bahadir, M. and Akkus, G.U. (2015) Study on the Impact of Elements in Water on the Diversity of Water Mites Acari, Hydrachnidia Species. Advances in Bioscience and Biotechnology, 64, 259-264. https://doi.org/10.4236/abb.2015.64025

[8] Di Sabatino, A., Smit, H., Gerecke, R., Goldschmidt, T., Matsumoto, N. and Cicolani, B. (2008) Global Diversity of Water Mites Acari, Hydrachnidia; Arachnida in Freshwater. Hydrobiologia, 5951, 303-315. https://doi.org/10.1007/s10750-007-9025-1

[9] Asçi, F., Bursali, A. and Özkan, M. (2007) Afyonkarahisar İli Su Kenesi (Acari; Hydrachnidia) Faunası. Süleyman Demirel University, Faculty of Egirdir Fisheries Journal, 2, 46-49.

[10] Skoog, D.A. and West, D.M. (1981) Principles of Instrumental Analysis, II.

[11] Gusler, G.M., Browne, T.E. and Cohen, Y. (1993) Sorption of Organics from Aqueous Solution onto Polymeric resins. Industrial \& Engineering Chemistry Research, 3211, 2727-2735. https://doi.org/10.1021/ie00023a040

[12] Pretsch, E., Bühlmann, P., Affolter, C., Pretsch, E., Bhuhlmann, P. and Affolter, C. (2009) Structure Determination of Organic Compounds. Vol. 13, Berlin, Springer.

[13] Weishaar, J.L., Aiken, G.R., Bergamaschi, B.A., Fram, M.S., Fujii, R. and Mopper, K. (2003) Evaluation of Specific Ultraviolet Absorbance as an İndicator of the Chemical Composition and Reactivity of Dissolved Organic Carbon. Environmental Science \& Technology, 3720, 4702-4708. https://doi.org/10.1021/es030360x

[14] Crews, P., Rodriquez, J., Jaspars, M. and Crews, R.J. (1998) Organic Structure Analysis. Oxford, New York, 23.

[15] Banaszak, A.T. and Trench, R.K. (1995) Effects of Ultraviolet UV Radiation on Marine Microalgal-İnvertebrate Symbioses. II. The Synthesis of Mycosporine-Like Amino Acids in Response to Exposure to UV in Anthopleura Elegantissima and Cassiopeia Xamachana. Journal of Experimental Marine Biology and Ecology, 1942, 233-250.

[16] Valiñas, M.S. and Helbling, E.W. (2015) Sex-Dependent Effects of Ultraviolet Radiation on the Marine Amphipod Ampithoe Valida Ampithoidae. Journal of Photochemistry and Photobiology B, 147, 75-82.

[17] Chuang, S.C. and Chen, J.H. (2013) Photooxidation and Antioxidant Responses in the Earthworm Amynthas Gracilis Exposed to Environmental Levels of Ultraviolet B Radiation. Comparative Biochemistry and Physiology Part A, 1643, 429-437.

[18] Siebeck, U.E. (2004) Communication in Coral Reef Fish, the Role of Ultraviolet Colour Patterns in Damselfish Territorial Behaviour. Animal Behaviour, 682, 273 282. 
Submit or recommend next manuscript to SCIRP and we will provide best service for you:

Accepting pre-submission inquiries through Email, Facebook, LinkedIn, Twitter, etc. A wide selection of journals (inclusive of 9 subjects, more than 200 journals)

Providing 24-hour high-quality service

User-friendly online submission system

Fair and swift peer-review system

Efficient typesetting and proofreading procedure

Display of the result of downloads and visits, as well as the number of cited articles Maximum dissemination of your research work

Submit your manuscript at: http://papersubmission.scirp.org/

Or contact abb@scirp.org 